\title{
Success and safety of sputum induction in the clinical setting
}

\author{
H. Vlachos-Mayer, R. Leigh, R.F. Sharon, P. Hussack, F.E. Hargreave
}

Success and safety of sputum induction in the clinical setting. H. Vlachos-Mayer, R. Leigh, R.F. Sharon, P. Hussack, F.E. Hargreave. C ERS Journals Ltd 2000.

ABSTRACT: It has previously been reported that sputum induction is successful and safe in the clinical research setting. The authors examined the success and safety of sputum induction in routine clinical practice in patients with asthma or chronic airflow limitation of varying severity.

Records of 304 patients with asthma and 25 with smoking related chronic airflow limitation were examined retrospectively. All had sputum induced as part of their routine clinical evaluation. When the baseline post salbutamol forced expiratory volume in one second (FEV1) was $\geq \mathbf{7 0 \%}$ predicted, the inductions consisted of inhalation of an aerosol of $3 \%, 4 \%$ and $5 \%$ saline, each given for $7 \mathrm{~min}$. If the FEV1 was $<70 \%$, or there were other reasons for concern, the inductions were initiated with normal saline for shorter periods. Inhalations were discontinued when sputum was obtained or when there was a fall in FEV1 $\geq \mathbf{2 0} \%$. Success was identified by obtaining nonsquamous total and differential cell counts containing macrophages, and safety by the fall in FEV1.

The overall success was $93 \%$. The procedure was safe even amongst patients with an FEV1 of $<60 \%$ and $<1 \mathrm{~L}$. Of 77 patients with an FEV1 between $40-59 \%, 8 \%$ fell by $\geq 20 \%$ and of 35 patients with an FEV1 $<40 \%, 6 \%$ fell by $20 \%$.

Carefully standardized sputum induction can be successful and safe in patients with asthma or chronic airflow limitation in clinical practice, even when moderate or severe airflow limitation is present.

Eur Respir J 2000; 16: 997-1000.
Induced sputum examination has been increasingly used in the research of asthma and other airway conditions. Results have shown that sputum cell counts have a place in clinical practice [1-6] but, because an inhaled aerosol of hypertonic saline is a bronchoconstrictor stimulus [7, 8], there have been concerns about the safety of sputum induction, particularly in patients with uncontrolled asthma or chronic airflow limitation. Safety has been addressed in three recent publications of research subjects with asthma, most of whom had a baseline forced expiratory volume in one second (FEV1) $>60 \%$ [9-11]. In the present study, the success and safety of sputum induction in clinical practice in patients with asthma of varying severity and in patients with smoking related chronic airflow limitation was investigated. Additional safety precautions were taken and a large number of patients with an FEV1 $<60 \%$ were included.

\section{Methods}

\section{Design}

This was a retrospective analysis of 329 consecutive sputum inductions, performed as part of the clinical evaluation of patients with asthma or chronic airflow limitation Allergy Clinic between September 1, 1997 and March 31, 1998. who were attending the Firestone Regional Chest and

\begin{abstract}
Asthma Research Group, Firestone Regional Chest and Allergy Unit, St. Joseph's Hospital and McMaster University, Hamilton, Ontario, Canada.
\end{abstract}

Correspondence: F.E. Hargreave

Firestone Regional Chest and Allergy Unit St. Joseph's Hospital

50 Charlton Avenue East

Hamilton, Ontario

Canada L8N 4A6

Fax: 0019055216158

Keywords: Asthma

chronic airflow limitation

sputum induction

Received: December 231999

Accepted after revision August 82000

\section{Patients}

The patients with asthma had episodic symptoms of chest tightness, wheezing or dyspnoea plus a provocative concentration causing a $20 \%$ fall in FEV 1 by methacholine (PC20) $<8 \mathrm{mg} \cdot \mathrm{mL}^{-1}$ (if the FEV1 was $\geq 70 \%$ predicted (pred)) or an improvement in FEV1 of $>12 \%$ after $200 \mu \mathrm{g}$ of inhaled salbutamol (if the FEV1 was $<70 \%$ pred) (table 1). The FEV1 after salbutamol was moderately reduced (40-59\% pred) in $69(23 \%)$ patients and severely reduced $(<40 \%)$ in $24(8 \%)$ patients. The severity of asthma, according to the level of treatment, was moderate in $48 \%$ and severe in $40 \%$ [12]. The patients with chronic airflow limitation had an onset of respiratory symptoms $>40 \mathrm{yrs}$ of age, $>15$ pack year smoking history, an FEV1 $<70 \%$ pred and an improvement in FEV1 $<10 \%$ after inhaled salbutamol. The FEV1 after salbutamol was moderately reduced in $8(32 \%)$ patients and severely reduced in 11 $(44 \%)$ patients.

\section{Procedures}

Clinical details, including sputum induction details, were collected from patient charts using standard patient record forms. In all cases, sputum induction was performed by trained technologists using the method described by PIN et al. [13], with modifications to improve safety [3]. Aerosols of hypertonic saline at $3 \%, 4 \%$, and $5 \%$ were each inhaled for 7 min via a Medix ultrasonic nebulizer 
(Clement Clarke International Ltd., Harlow Essex, UK) which has an output of $0.87 \mathrm{~mL} \cdot \mathrm{min}^{-1}$ and an aerosol mass median diameter of $5.58 \mu \mathrm{m}$. Patients were asked to cough into a container after each period. The standard safety precautions were to premedicate with $200 \mu \mathrm{g}$ of inhaled salbutamol, then to measure the FEV1 at baseline and after each period of saline induction, not to increase the dose of saline if there was a fall in FEV1 of $10-19 \%$, and to discontinue saline inductions if the FEV1 fell $\geq 20 \%$. In the case of an excessive fall in FEV1 ( $\geq 20 \%)$ further salbutamol was administered and the patient was kept in the laboratory until the FEV1 had returned to within $5 \%$ of baseline. If the baseline FEV1 was $<70 \%$ pred, further safety precautions were taken by starting the inductions with normal saline and using shorter times of inhalation, e.g. $30 \mathrm{~s}$ followed by 1, 2 and $4 \mathrm{~min}$ [3]. Other indices for caution were a previous fall in FEV $1 \geq 20 \%$ during sputum induction, the presence of significant airway reversibility ( $\geq 12 \%$ ), or the presence of a clinical exacerbation. Where there was concern about safety, the inhalations were discontinued when the expectorate was considered to contain enough sputum $(>70 \mathrm{mg})$ for examination. Sputum was selected from the expectorate and processed within $2 \mathrm{~h}$ as described by PizzichinI et al. [14]. Successful inductions was defined as those in which nonsquamous total and differential cell counts were

a)

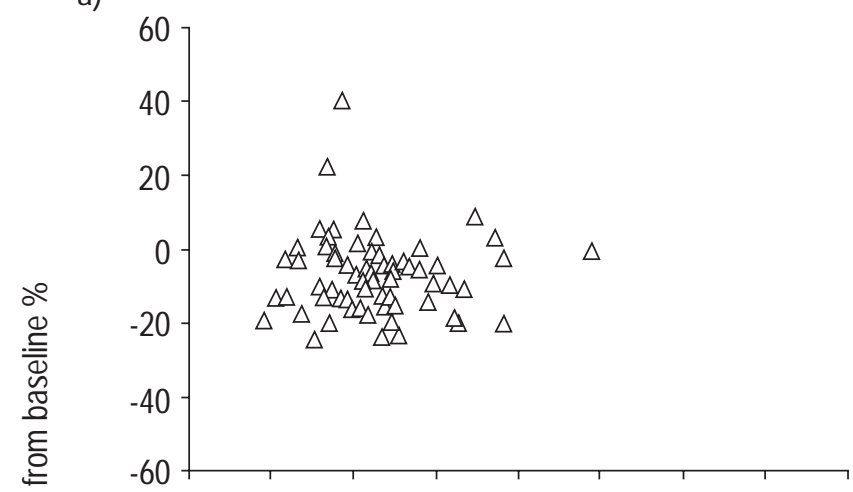

c)

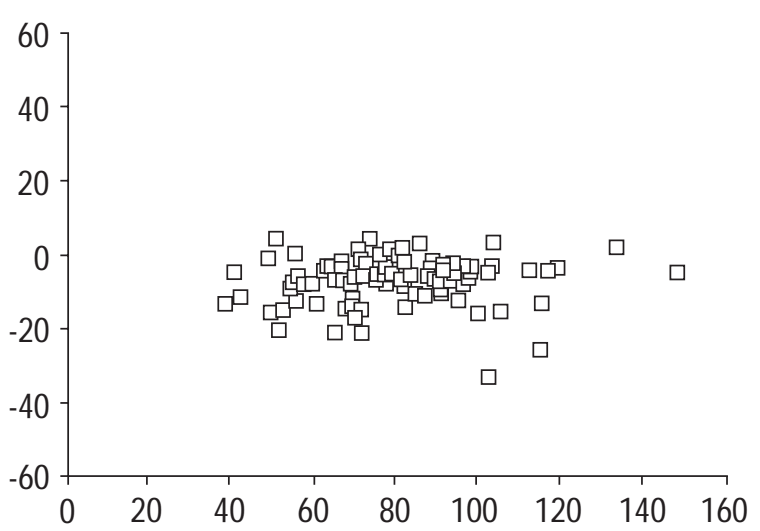

obtained which contained macrophages. Squamous cell contamination was $<20 \%$ and cell viability was $>40 \%$.

\section{Data analysis}

Descriptive statistics were used to summarize the baseline characteristics of the patients and the results were expressed as mean \pm standard deviation (SD). Success, medication use, final saline concentration administered, the incidence of excessive falls in FEV1 per group and other noncontinuous data were expressed as counts or percentages. Pearson's correlation coefficient was used to evaluate the change between the pre-induction post salbutamol FEV1 and the value after the last concentration of saline. Multiple linear regression was used to identify potential risk factors to predict a fall in FEV1 during sputum induction. Significance was accepted at the $95 \%$ level.

\section{Results}

Sputum induction was successful in $93 \%$ of all patients regardless of the diagnosis, degree of airflow limitation or the concentration of saline inhaled. Amongst those with asthma, the highest concentration of saline inhaled was

b)

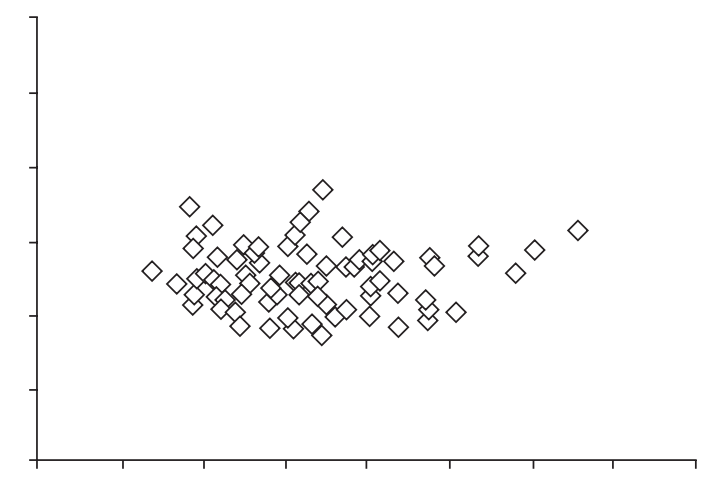

d)

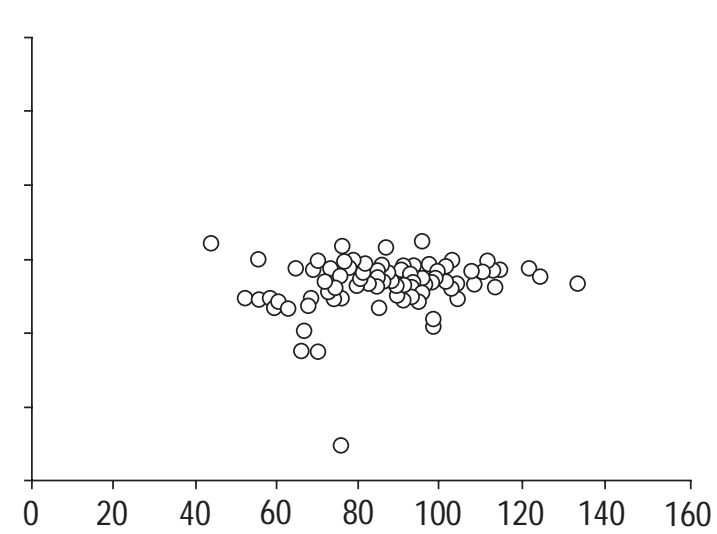

Baseline FEV1 \% predicted

Fig. 1. - Individual change in FEV1 values from baseline (\%) during sputum induction, plotted against baseline FEV1 \% predicted. Different symbols represent the highest saline concentration administered. a) $\triangle$ : isotonic saline; b) $\diamond: 3 \%$ saline; c) $\square: 4 \%$ saline; d) $\bigcirc: 5 \%$ saline. FEV1: forced expiratory volume in one second. 
Table 1. - Patient characteristics

\begin{tabular}{lcc}
\hline & Asthma & CAL \\
\hline Subjects n & 304 & 25 \\
Age yrs & $50 \pm 16.5$ & $64 \pm 11.3$ \\
Male n & 144 & 11 \\
FEV1 \% pred & $73 \pm 23.5$ & $46 \pm 17.5$ \\
No steroid use & $35(12)$ & $8(32)$ \\
Inhaled steroid (without prednisone) & $147(48)$ & $17(68)$ \\
Inhaled steroid and prednisone & $122(40)$ & $0(0)$ \\
Long acting $\beta_{2}$ & $75(25)$ & $4(16)$ \\
\hline
\end{tabular}

Data are presented as mean $\pm \mathrm{SD}$. Data in parentheses are presented as $\mathrm{n}(\%)$. CAL: chronic airflow limitation; FEV1: forced expiratory volume in one second (values reported are those at baseline; postbronchodilator, pre-induction).

$0.9 \%$ in $17 \%, 3 \%$ in $26 \%, 4 \%$ in $29 \%$ and $5 \%$ in $28 \%$ of patients; amongst those patients with chronic airflow limitation, it was $0.9 \%$ in $56 \%, 3 \%$ in $24 \%, 4 \%$ in $4 \%$ and $5 \%$ in $16 \%$. Excessive bronchoconstriction, defined as a fall in FEV 1 of $\geq 20 \%$, only occurred in $23(8 \%)$ of all patients (fig. 1). Seven of these 23 patients were on long acting $\beta_{2}$-agonists as part of their maintenance treatment but, in a regression model, neither this or methacholine $\mathrm{PC} 20$ could be identified as risk factors for a fall in FEV1. Of 77 patients with an FEV1 between $40-59 \%, 8 \%$ fell by $\geq 20 \%$ and of 35 patients with an FEV $1<40 \%, 6 \%$ fell by $\geq 20 \%$. There was no correlation between the maximal fall in FEV1 and baseline (postbronchodilator) FEV1 \% pred $(r=0.12)$. No subject developed refractory bronchoconstriction or required emergency treatment.

\section{Discussion}

This is the first formal investigation of the success and safety of the method of sputum induction described by PIN et al. [13] and modified by Pizzichini et al. [14] in clinical practice. Sputum induction performed carefully by trained staff in routine clinical practice was successful in $93 \%$ of patients with asthma or chronic airflow limitation, in spite of most $(n=239)$ patients not receiving the maximum saline concentration and many $(n=66)$ only receiving isotonic saline. Excessive bronchoconstriction only occurred in $8 \%$ of patients with asthma and was not predicted from the baseline postbronchodilator FEV1. All 23 patients who had a fall in FEV1 $>20 \%$ following sputum induction were treated with additional inhaled salbutamol $(200-400 \mu \mathrm{g})$, and in all cases their FEV1 returned to within $5 \%$ of the baseline (postbronchodilator) value within $30 \mathrm{~min}$. The results indicate that sputum induction can be carried out safely and successfully in clinical practice, even in the presence of moderate or severe airflow limitation.

The safety results were slightly better than those reported by WONG et al. [9], similar to those of HUNTER et al. [11] and slightly worse than those reported by DE LA FUENTE et al. [10], while the success was similar to that reported in the three studies described above. This is not surprising, when a comparison is made between the subjects studied and the procedures used in the three studies. Wong et al. [9] studied patients with asthma with a postbronchodilator FEV $1>60 \%$ and all their patients inhaled an aerosol of 3\% hypertonic saline for $20 \mathrm{~min}$ before repeating the FEV1. As a result, earlier falls in
FEV1 were not detected and a higher occurrence of excessive falls were observed. This may be the reason that they were able to illustrate that the saline-induced falls in FEV1 were greater when the baseline FEV1 was lower, a relationship not observed in other studies, including the present one. DE LA FUENTE et al. [10] studied a more severe group of asthmatic subjects with an FEV1 $>1$ L. They used the method of induction described by PIN et al. [13], giving 3\% saline, followed by $4 \%$ and then $5 \%$, for $5 \mathrm{~min}$ with each saline concentration given twice. However, they did not proceed to the next concentration if the FEV1 fell by $10 \%$ and they discontinued the inhalations if adverse symptoms developed. HUNTER et al. [11] studied a mild group of asthmatic subjects with a mean FEV1 of $83 \%$, their induction procedure was similar to DE LA FUENTE et al. [10] except each concentration was only given once. In the present study, a similar range of asthma severity as used by DE LA FUENTE et al. [10], was examined however, it also included a large number of patients with moderate to severe airflow limitation. During these inductions additional safety precautions were taken; if the baseline postbronchodilator FEV1 was $<70 \%$, or if there were suggestions of more severe airway hyperresponsiveness, the inhalations with normal saline were initiated for shorter periods of time. The inductions were also discontinued when an apparently adequate macroscopic sputum sample was produced.

The results of the present study, specifically illustrate the safety of the method of sputum induction used. Many of the patients had severe asthma; 112 inductions were carried out on patients with a prebronchodilator FEV $1<60 \%$, and 40 inductions were performed on patients with a prebronchodilator FEV $1<1 \mathrm{~L}$. In spite of this, only $8 \%$ of patients had excessive bronchoconstriction (fall in FEV1 $\geq 20 \%$ ), and none of these were in the group with moderate to severe airflow limitation. Only two patients, both of whom had asthma, had a fall in FEV1 $>30 \%$. One had a baseline FEV1 of $103 \%$ pred, and the induction consisted of $3 \%$ for 2 runs and $4 \%$ for one run; there was a $10 \%$ fall in FEV1 following the first run which did not worsen after the second run but fell to $32 \%$ after the third run. The other patient had a baseline FEV1 of $75 \%$ pred and received $3 \%, 4 \%$ and $5 \%$ saline; the FEV1 fell by $9 \%$ after $4 \%$ saline, and by $50 \%$ after $5 \%$ saline. The airway constriction was quickly reversed by inhaled salbutamol in both cases. These infrequent episodes of more severe induced airway constriction highlight the importance of being cautious, having resuscitation equipment available in the laboratory, and for having a responsible physician in the building when the inductions are performed. To conclude, the method of sputum induction used in this report can be successfully and safely performed by trained staff in clinical practice, even in patients with moderate or severe asthma or chronic airflow limitation.

\footnotetext{
Acknowledgements. The authors would like to thank M. Morris, D. Kamada and D. O'Shaughnessey for performing the sputum inductions. Thanks also to A. Efthimiadis for supervising the examination of the sputum, T. Whitely for her help in organizing patient records and L. Burch for secretarial assistance. R. Leigh is a South African Pulmonology Society-Boehringer Ingelheim Fellow.
} 


\section{References}

1. Brightling CE, Ward R, Goh KL, Wardlaw AJ, Pavord ID. Eosinophilic bronchitis is an important cause of chronic cough. Am J Respir Crit Care Med 1999; 60: 406-410.

2. Lemiere C, Pizzichini MMM, Balkisoon R, et al. Diagnosing occupational asthma: use of induced sputum. Eur Respir J 1999; 13: 482-488.

3. Pizzichini MMM, Pizzichini E, Clelland L, et al. Sputum in severe exacerbations of asthma: kinetics of inflammatory indices after prednisone treatment. Am J Respir Crit Care Med 1997; 155: 1501-1508.

4. Pizzichini E, Pizzichini MMM, Gibson P, et al. Sputum eosinophilia predicts benefit from prednisone in smokers with chronic obstructive bronchitis. Am J Respir Crit Care Med 1998; 158: 1511-1517.

5. Pizzichini MM, Pizzichini E, Parameswaran $\mathrm{K}$, et al. Nonasthmatic chronic cough: No effect of treatment with an inhaled corticosteroid in patients without sputum eosinophilia. Can Respir J 1999; 6: 323-330.

6. Parameswaran K, Leigh R, Hargreave FE. Sputum eosinophil count to assess compliance with corticosteroid therapy in asthma. J Allergy Clin Immunol 1999; 104: 502-503.

7. Anderson SD, Schoeffel RE, Finney M. Evaluation of ultrasonically nebulized solutions for provocation testing in patients with asthma. Thorax 1983; 38: 284-291.

8. Boulet LP, Legris C, Thibeault L, Turcotte H. Comparative bronchial responses to hyperosmolar saline and methacholine in asthma. Thorax 1987; 42: 953-958.

9. Wong HH, Fahy JV. Safety of one method of sputum induction in asthmatic subjects. Am J Respir Crit Care Med 1997; 156: 299-303.

10. de la Fuente PT, Pomagnoli M, Godard P, Bousquet J, Chanez P. Safety of inducing sputum in patients with asthma of varying severity. Am J Respir Crit Care Med 1998; 157: 1127-1130.

11. Hunter CJ, Ward R, Woltmann G, Wardlaw AJ, Pavord ID. The safety and success rate of sputum induction using a low output ultrasonic nebuliser. Respir Med 1999; 93: 345-348.

12. Boulet L-P, Becker A, Bérubé D, Beveridge R, Ernst P on behalf of the Canadian Asthma Consensus Group. Canadian Asthma Consensus Report, 1999. CMAJ 1999; 161 (Suppl. 11): S1-S61.

13. Pin I, Gibson PG, Kolendowwicz R, et al. Use of induced sputum cell counts to investigate airway inflamation in asthma. Thorax 1992; 47: 25-29.

14. Pizzichini E, Pizzichini MMM, Efthimiadis A, et al. Indices of airway inflammation in induced sputum: reproducibility and validity of cell and fluid phase measurements. Am J Respir Crit Care Med 1996; 154: 308-317. 